Manuscript received April 4, 2018; accepted for publication July 17 , 2018; published online December 20, 2018. Issue published September 1, 2020.

1 Laboratory for Biomimetic Membranes and Textiles, Swiss Federal Laboratories for Materials Science and Technology, Lerchenfeldstrasse 5, St. Gallen 9014, Switzerland, (1) https:// orcid.org/0000-0002-2812-9020 (S.K.)

2 Mountain Equipment Cooperative, 1077 Great Northern Way, Vancouver, BC V5T 1E1, Canada

${ }^{3}$ Laboratory for Biomimetic Membranes and Textiles, Swiss Federal Laboratories for Materials Science and Technology, Lerchenfeldstrasse 5, St. Gallen 9014, Switzerland (Corresponding author), e-mail:

Martin.Camenzind@empa.ch
Shelley Kemp, ${ }^{1}$ Xiaoan Shen, ${ }^{2}$ René Rossi, ${ }^{1}$ and Martin Camenzind ${ }^{3}$

\section{Thermal Resistance of Air-Filled Mattresses: Measurement Repeatability and the Effect of Selected Test Parameters}

\section{Reference}

S. Kemp, X. Shen, R. Rossi, and M. Camenzind, "Thermal Resistance of Air-Filled Mattresses: Measurement Repeatability and the Effect of Selected Test Parameters," Journal of Testing and Evaluation 48, no. 5 (September/October 2020): 3894-3907. https://doi.org/10.1520/ JTE20180238

\section{ABSTRACT}

There is no standardized test method specifically for determining the thermal resistance (R-value) of air-filled mattresses. Unacceptable inter- and intra-laboratory variations in round-robin testing have been attributed to differences in the test apparatus and test parameters used. To identify relevant sources of variation, the repeatability of the guarded hotplate apparatus (in a double plate configuration) was first characterized, and then the effect of modifying selected test parameters on mattress thickness and thermal resistance was investigated. Two mattress types, in two different sizes, were examined: one contained air only while the other contained air plus a nonwoven polyester fill. It was found that repeatable outcomes could be attained when using the guarded hotplate apparatus (95\% repeatability limit of less than $0.08 \mathrm{~m}^{2} \mathrm{~K} / \mathrm{W}$ for all mattresses tested). The modification of test parameters had significant effects on mattress thickness or R-value, or both. External pressure, the temperature difference across the specimen, supplementary insulation, mattress size, and environmental conditions affected both the thickness and R-value of the test mattresses. Inflation pressure, over the range tested, did not have a significant effect on the $\mathrm{R}$-value but did influence mattress thickness. This work highlights the need for the standardization of the test apparatus and test parameters and will aid in the development of a standardized test method.

\section{Keywords}

thermal resistance, air mattress, camping mattress, standardization, repeatability, pressure 


\section{Introduction}

Consumers select air mattresses based on a number of factors, including size, weight, comfort (thermal, tactile, and pressure), durability, cost, and intended use. The types of air mattresses commercially available for use in outdoor environments (i.e., camping) are becoming more diverse. These mattresses vary in size, composition (external textiles and internal fillers), and construction. Popular construction types include air-filled, air-filled with internal insulation, air-filled with radiant reflective materials, self-inflating homogeneous foam, and selfinflating foam with coring.

Currently, there is no published standard test method specifically for determining the thermal resistance (R-value) of air-filled mattresses (camping mattresses). Various thermal resistance standards have been adapted by different laboratories for this purpose, which has resulted in interlaboratory inconsistencies in the instrumentation and test parameters used. Indeed, preliminary round-robin testing has indicated excessive variability in $\mathrm{R}$-value results from various laboratories [1]. Three mattress types were investigated by four laboratories using a guarded hotplate, thermal manikin, tog bed, and tog meter. For each mattress type, the coefficients of variation were in excess of $22 \%$, and in one instance the reproducibility limit ${ }^{4}$ was $0.85 \mathrm{~m}^{2} \mathrm{~K} / \mathrm{W}\left(4.8 \mathrm{hr} . \mathrm{ft}^{2}{ }^{\circ} \mathrm{F} / \mathrm{Btu}\right)[1,2]$. Test parameters such as heat flow direction (heat-down or heat-up), mattress size, external pressure/load, inflation pressure, temperature difference across the mattress, environmental conditions, and use of supplementary insulation are potential sources of variation.

As with all test methods, the measurement of the R-value using the guarded hotplate apparatus has its limitations. However, small-scale bench tests, such as the guarded hotplate apparatus, are generally more reproducible, economical, and easier to use than large-scale manikin tests or human participant trials. For the guarded hotplate apparatus, three fundamental configurations are defined by current thermal resistance standards: (1) the single-plate method, in which the outer face of a single specimen is exposed to ambient conditions; (2) the double-plate method, in which a single specimen is positioned between two plates; and (3) the dual-specimen method, where two specimens are tested in parallel [3-12]. The double plate configuration in a heat-down mode is considered to be the most representative of end-use conditions for outdoor air mattresses [1] in that the mattress is positioned between a warm user and the cooler ground beneath, and a relatively constant pressure is applied to the mattress by the user. When possible, the test parameters should reflect the typical conditions of use.

Typically, the surface area of an off-the-shelf air mattress is greater than the plate area of the guarded hotplate apparatus. However, for testing, an air mattress cannot simply be cut to the desired size. Thus, the test specimen must be either the mattress in its entirety or custom-made by the manufacturer to a specified length and width. There are advantages and disadvantages to both approaches. With custom-size mattresses, there are additional costs for the manufacturer. With a full-size mattress, the test specimen is representative of that available on the market; however, the impact of the heat transfer between the test and non-test portion of the air mattress (by convection or conduction, or both) on the resultant R-value is complex and not yet characterized (see Fig. 1). The extent of this heat loss may be influenced by factors such as the size, construction, and composition of the mattress (external textiles and internal fillers), size of the test plate (measuring plate plus thermal guard), and surrounding environmental conditions.

The external pressure applied to an air mattress by a supine human is variable depending on factors such as the individual's body weight and distribution, size of the contact area, mattress characteristics, and methodology and instrumentation used to record the pressure [13-15]. The pressures recorded on air-filled mattresses are typically between 1.5 and $3.5 \mathrm{kPa}$ and are dependent on the inflation pressure [16,17]. There is also a substantial degree of variability in the preferred firmness of the sleeping surface between individuals $[18,19]$. For example,

\footnotetext{
4"The value below which the absolute difference between two test results obtained under reproducibility conditions may be expected to occur with a probability of approximately 0.95 (95\%)" [2].
} 
FIG. 1 Schematic of the temperature gradients involved when testing full-size air mattresses: 1. experimental temperature gradient established by the upper and lower plate, 2. temperature gradient between the test portion (the area covered by the test plates) and non-test portion (area not covered by the test plates), and 3. the temperature gradient between the non-test portion of the mattress and environment.

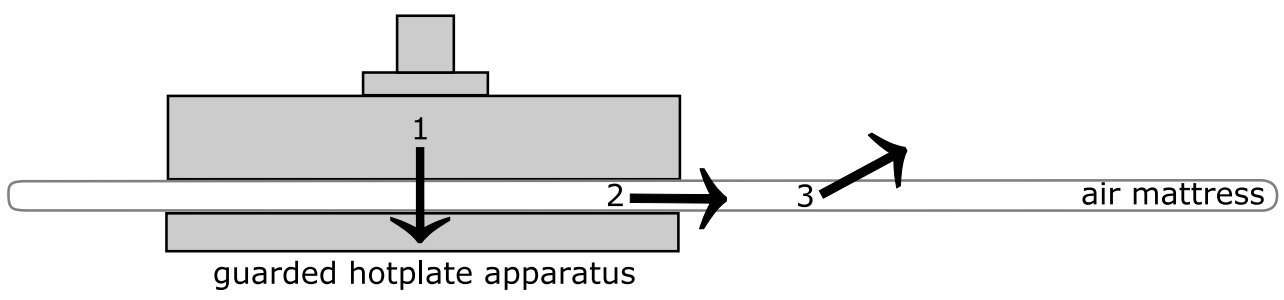

for the NEMO Cosmo $25 \mathrm{~L}$ mattress (NEMO Equipment, Dover, $\mathrm{NH}$ ), the preferred pressure was $3.6 \pm 1.2 \mathrm{kPa}$ $($ sample size $=11)$ [19]. Furthermore, different mattress types, even when inflated to the same internal pressure, may differ in their perceived firmness because of mattress construction and composition.

Current thermal resistance standards commonly prescribe a hotplate temperature of $35^{\circ} \mathrm{C}$, which is an approximation of skin temperature (e.g., Refs. $[5,7,11]$ ). The recommended temperature difference across the specimen is typically in the order of $5^{\circ} \mathrm{C}$ to $20^{\circ} \mathrm{C}$ but is up to $50^{\circ} \mathrm{C}$ for thick materials with high R-values (e.g., Refs. $[3,6])$. A small temperature difference increases the risk of "temperature-difference measurement errors" [3], while a high temperature difference is often limited by the capability of the apparatus to generate sufficient power while maintaining stable temperatures [3]. Additionally, when a large difference is selected, the time taken for the measurement to reach a steady state, known as the settling time, is increased.

Textile tests are generally conducted in standard environmental conditions as defined by ISO 139, Textiles Standard Atmospheres for Conditioning and Testing, or ASTM D1776/D1776M-16, Standard Practice for Conditioning and Testing Textiles [20,21]. Air mattresses are often designed for use in low-temperature environments, and thus some manufacturers have expressed a desire to test at similar ambient conditions. However, the effects of the environmental temperature on the resultant $\mathrm{R}$-value and the additional cost of testing in a climate chamber must be considered prior to standardization.

Standardization aims to ensure results are comparable; that is, repeatable within laboratories and reproducible across laboratories. In the context of air mattresses, standardization benefits consumers by facilitating informed decisions regarding performance expectations and benefits manufacturers by enabling product improvement through enhanced understanding of the impacts of mattress design and composition [22]. To support the development of such a standard, a better understanding of the sources of intra- and interlaboratory variation is required.

There were two objectives of this work. The first objective was to quantify the repeatability of the guarded hotplate test apparatus when testing air-filled mattresses. The second objective was to investigate the effect of selected test parameters (temperature difference, inflation pressure, external pressure, mattress size, environmental conditions, and supplementary insulation) on the mattress thickness and thermal resistance.

\section{Method}

For both study objectives (part one, test method repeatability, and part two, the effect of selected test parameters), the same test apparatus, test procedure, and mattress types were used, as outlined in the following sections.

\section{TEST APPARATUS}

The thermal properties of the selected air mattresses were determined using a double-plate guarded hotplate apparatus constructed in-house (see Fig. 2). The apparatus conforms to ISO 8302:1991, Thermal 
Insulation - Determination of Steady-State Thermal Resistance and Related Properties - Guarded Hot Plate Apparatus [3]. The upper plate (measurement plate plus guard) was maintained at a higher temperature than the lower plate, creating a defined temperature difference across the specimen. The upper plate applied a defined pressure to the specimen throughout the measurement. The upper and lower plates $(0.6 \mathrm{~m}$ by $0.6 \mathrm{~m})$ are composed of aluminum. The upper plate is comprised of a centered measurement plate $\left(0.32 \mathrm{~m}\right.$ by $\left.0.32 \mathrm{~m} ; 0.10 \mathrm{~m}^{2}\right)$ surrounded by a thermal guard $(0.14 \mathrm{~m}$ wide). The lower plate is a single plate, cooled using Peltier elements. The thermal guard is set to the same temperature as the measurement plate to mitigate lateral heat loss.

Prior to testing, the power and temperature sensors were calibrated in-house. The accuracy of the instrumentation and test method was checked using a standard reference material (NIST SRM 1450D, Fibrous-Glass Board, for Thermal Conductivity from $280 \mathrm{~K}$ to $340 \mathrm{~K} ; 0.60 \mathrm{~m}$ by $0.60 \mathrm{~m}$ by $0.25 \mathrm{~m}$ ). The standard reference material was tested using the default test parameters, and the results were within $3 \%$ of the target value. The results for the standard reference material and air mattress specimens were not adjusted for contact resistance, which was found to be negligible.

\section{MATTRESS TYPES}

Two mattress types, each in two sizes (full-size and custom-size), were used. Mattress Type 1 was an air-filled mattress with a lengthwise baffle. Mattress Type 2 contained a nonwoven polyester within the air chambers but was otherwise similar to Mattress Type 1 in its construction and size. Thus, air is able to move freely by natural convection within the chambers of Mattress Type 1, whereas convection may be mitigated by the filler within Mattress Type 2. The composition, construction, mass, and dimensions of each mattress type are provided in Table 1. All mattresses (sample size $=3$ for each) were manufactured by Mountain Equipment Co-op (Vancouver, Canada; see Fig. 3). The full-size mattresses were off-the-shelf, and the custom-size mattresses were manufactured to approximately match the test apparatus plate size. All of the mattresses were new. Using these mattress type-size combinations permitted examination of the potential effects of heat transfer between the test and non-test portion of the mattress. Testing a broader range of mattresses is relevant but beyond the scope of this work in that here, the focus was on the effects of test parameters rather than the differences between mattresses, per se.

FIG. 2

Schematic of the doubleplate guarded hotplate apparatus: 1. hoist, 2 . thermal guard, 3. measuring plate, 4 . air mattress specimen, 5 . lower cold plate, 6 . support structure with Peltier elements, 7. measurement of power across the heating coil, and 8 . measurement of temperature with thermistors distributed across the plate. (a) Side view of test apparatus, (b) lower plate, and (c) upper plate.

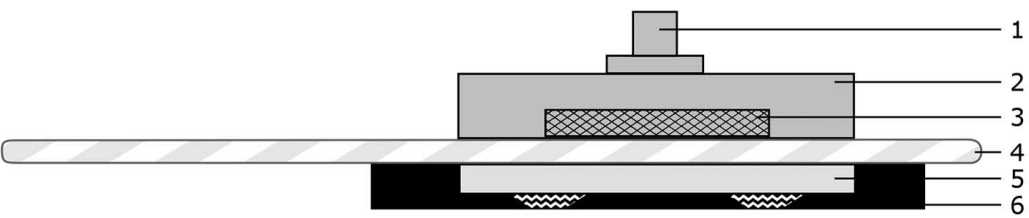

(a)

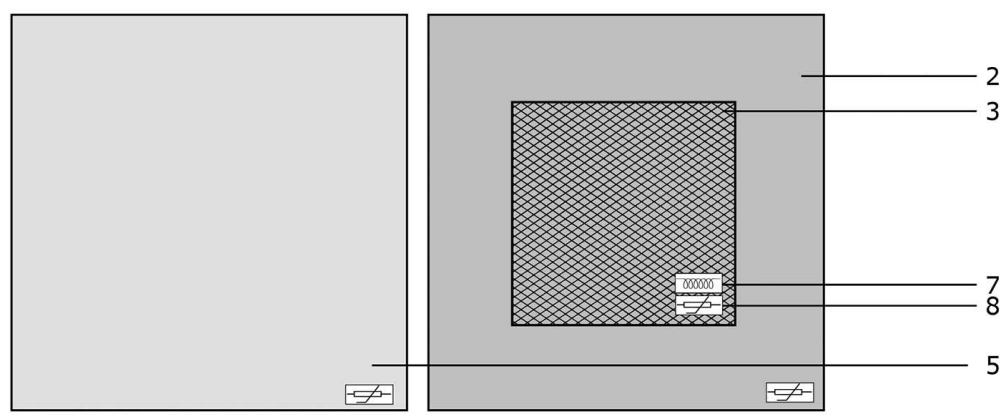

(b)

(c) 
TABLE 1

Mattress properties.

\begin{tabular}{|c|c|c|c|c|c|c|c|c|}
\hline Mattress & $\begin{array}{l}\text { Composition of } \\
\text { Top Layer }\end{array}$ & $\begin{array}{l}\text { Composition of } \\
\text { Bottom Layer }\end{array}$ & $\begin{array}{l}\text { Composition } \\
\text { of Fill }\end{array}$ & Baffle & Mass, $\mathrm{g}$ & $\begin{array}{l}\text { Length, } \\
\mathrm{mm}^{\mathrm{b}}\end{array}$ & $\begin{array}{l}\text { Width, } \\
\mathrm{mm}^{\mathrm{b}}\end{array}$ & $\begin{array}{c}\text { Thickness, } \\
\mathrm{mm}^{\mathrm{c}}\end{array}$ \\
\hline 1 Full-size & $\begin{array}{l}75 \mathrm{D} \text { polyester } \\
\text { with } \mathrm{TPU}^{\mathrm{a}} \text { film }\end{array}$ & $\begin{array}{l}75 \text { D polyester } \\
\text { with TPU film }\end{array}$ & no fill & $\begin{array}{l}\text { lengthwise, } \\
\text { film }\end{array}$ & $752.3 \pm 5.8$ & $2,023 \pm 1$ & $599 \pm 3$ & $67.4 \pm 0.3$ \\
\hline 1 Custom-size & $\begin{array}{l}75 \mathrm{D} \text { polyester } \\
\text { with TPU film }\end{array}$ & $\begin{array}{l}75 \mathrm{D} \text { polyester } \\
\text { with TPU film }\end{array}$ & no fill & $\begin{array}{l}\text { lengthwise, } \\
\text { film }\end{array}$ & $253.3 \pm 0.5$ & $712 \pm 1$ & $625 \pm 5$ & $72.6 \pm 0.9$ \\
\hline 2 Full-size & $\begin{array}{l}75 \mathrm{D} \text { polyester } \\
\text { with TPU film }\end{array}$ & $\begin{array}{l}75 \mathrm{D} \text { polyester } \\
\text { with TPU film }\end{array}$ & $\begin{array}{l}\text { nonwoven } \\
\text { polyester }\end{array}$ & $\begin{array}{l}\text { lengthwise, } \\
\text { film }\end{array}$ & $1,014.0 \pm 4.5$ & $2,020 \pm 2$ & $612 \pm 6$ & $67.7 \pm 1.6$ \\
\hline 2 Custom-size & $\begin{array}{l}75 \text { D polyester } \\
\text { with TPU film }\end{array}$ & $\begin{array}{l}75 \mathrm{D} \text { polyester } \\
\text { with TPU film }\end{array}$ & $\begin{array}{l}\text { nonwoven } \\
\text { polyester }\end{array}$ & $\begin{array}{l}\text { lengthwise, } \\
\text { film }\end{array}$ & $347.7 \pm 1.2$ & $703 \pm 1$ & $621 \pm 1$ & $73.4 \pm 0.8$ \\
\hline Down quilt & $50 \mathrm{~d}$ nylon & $50 \mathrm{~d}$ nylon & $\begin{array}{l}8515 \text { down } \\
650 \mathrm{FP}\end{array}$ & box baffle & $\begin{array}{l}\text { fill weight: } \\
\sim 200 \mathrm{~g} / \mathrm{m}^{2}\end{array}$ & - & - & - \\
\hline
\end{tabular}

Note: Values are mean \pm standard deviation (SD); ${ }^{\mathrm{a}} \mathrm{TPU}$ : thermoplastic polyurethane; ${ }^{\mathrm{b}}$ Approximate dimensions are from seam-to-seam on the ground side, when inflated to $3.5 \mathrm{kPa}{ }^{c}$ Thickness measured when the specimen was mounted in the guarded hotplate, under $2 \mathrm{kPa}$ of pressure. For all specimens, the thickness is less than the maximum thickness for the apparatus, according to ISO 8302:1991 [3].

FIG. 3

Typical examples of the mattresses tested:

(a) Mattress 1 full-size,

(b) Mattress 2 full-size,

(c) Mattress 1 custom-

size, and (d) Mattress 2

custom-size (scale is

$150 \mathrm{~mm}$ by $305 \mathrm{~mm}$ ).

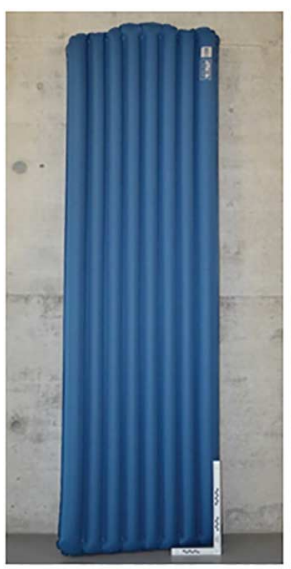

(a)



(b)

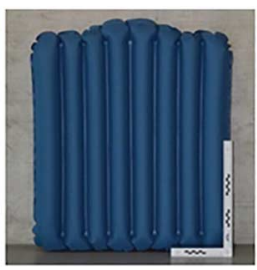

(c)

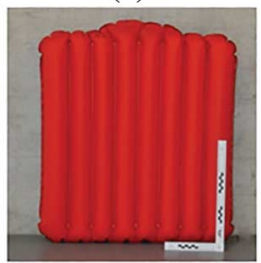

(d)

\section{TEST PROCEDURE}

The air mattresses were inflated to test pressure using compressed air and then conditioned for 24 hours at $20 \pm 2^{\circ} \mathrm{C} /$ $65 \pm 4 \%$ relative humidity $(\mathrm{RH})$ [20]. The pressure was tested again immediately prior to testing and adjusted as required. Each mattress was tested in the horizontal plane, with the side the user lies on orientated toward the upper plate. The torso region of each full-size mattress was tested. Tests were conducted in a pseudo-randomized order, allowing for the following exceptions: (1) to ensure that each mattress was conditioned prior to testing, the same mattress was never tested consecutively; and (2) tests conducted in cold environmental conditions were grouped, yet the order of the tests within the group were randomized. The upper plate was lowered onto the air mattress and allowed to stabilize for approximately 5 minutes, after which the thickness of the test portion of the mattress under load was recorded. The thickness was measured manually at each corner of the plate and averaged.

Steady state was defined to be within the following parameters: temperature within $0.05^{\circ} \mathrm{C}$ of the target value, with a maximum slope of $0.05^{\circ} \mathrm{C} / \mathrm{s}$, and power within $0.2 \mathrm{~W}$, with a maximum slope of $0.01 \mathrm{~W} / \mathrm{s}$. The settling time varied (typically within 60 to 120 minutes) depending on, for example, the mattress properties, selected test 
parameters, and time taken to exchange test specimens. The data acquisition system (NI DAQ, National Instruments, Austin, TX) sampled data (temperature and power) at a rate of 1,000 samples per second. These data were averaged to provide a readout at $0.1 \mathrm{~Hz}$ and filtered using a Savitzky-Golay filter (every 10 seconds, width $=6$, order $=3$ ). Data were collected at steady state for two consecutive 60 -minute time periods. The average power required to maintain the measurement plate at a constant temperature was calculated over the final 60 minutes of each test. Thermal resistance was calculated as $\mathrm{R}$-value $=A .(\Delta T / H)$, where $\mathrm{R}$-value $=$ thermal resistance $\left(\mathrm{m}^{2} \mathrm{~K} / \mathrm{W}\right), A=$ area of the measurement plate $\left(\mathrm{m}^{2}\right), \Delta T=$ temperature difference between the upper and lower plate $\left({ }^{\circ} \mathrm{C}\right.$ or $\left.\mathrm{K}\right)$, and $H=$ mean power input (W) [22]. Results for thermal resistance were reported in the SI unit of $\mathrm{m}^{2} \mathrm{~K} / \mathrm{W}$. The imperial unit of $\mathrm{hr} . \mathrm{ft}^{2}{ }^{\circ} \mathrm{F} / \mathrm{Btu}$, a popular unit in the outdoor equipment market, is equal to $5.678 \times \mathrm{m}^{2} \mathrm{~K} / \mathrm{W}$.

\section{PART ONE-TEST METHOD REPEATABILITY}

The within-laboratory repeatability was assessed under repeatability conditions ${ }^{5}$ using four mattresses (one fulland one custom-size mattress of each type, as described in Table 1). Each specimen was tested 10 times with the following test parameters: temperature difference, $15^{\circ} \mathrm{C}$ (upper plate $35^{\circ} \mathrm{C}$, lower plate $20^{\circ} \mathrm{C}$ ); inflation pressure, $3.5 \mathrm{kPa}$; external pressure, $2 \mathrm{kPa}$; standard atmospheric conditions $\left(20 \pm 2^{\circ} \mathrm{C} / 65 \pm 4 \% \mathrm{RH} /\right.$ still air $)$; and without supplementary insulation.

\section{PART TWO-THE EFFECT OF SELECTED TEST PARAMETERS}

For Part Two, the effect of the selected test parameters (temperature difference, inflation pressure, external pressure, mattress size, environmental conditions, and supplementary insulation) was investigated for both mattress types. To accomplish this, certain parameters were used as default settings and, in turn, one parameter was modified according to the test condition. The default parameters were as follows: full-size mattresses; inflation pressure, $3.5 \mathrm{kPa}$; external pressure, $2 \mathrm{kPa}$; temperature difference, $15^{\circ} \mathrm{C}$ (upper plate $35^{\circ} \mathrm{C}$, lower plate $20^{\circ} \mathrm{C}$ ); no supplementary insulation; and standard atmospheric conditions $\left(20 \pm 2^{\circ} \mathrm{C} / 65 \pm 4 \% \mathrm{RH}\right.$, still air). Tests were conducted in triplicate. When possible, the test parameters were selected to reflect potential conditions of use.

- Temperature difference. Each mattress was tested at three temperature differences. At each temperature difference, the upper plate remained at $35^{\circ} \mathrm{C}$, and the temperature of the lower plate was adjusted in order to achieve differences of $5^{\circ} \mathrm{C}, 10^{\circ} \mathrm{C}$, and $15^{\circ} \mathrm{C}$ across the specimen. Larger temperature differences could not be reached with the current instrumentation.

- External pressure. Each mattress was tested at three external pressure levels: 0, 2, and $3 \mathrm{kPa}$. At $0 \mathrm{kPa}$ of pressure, the plate was fixed at the point where it first contacted the mattress. At 2 and $3 \mathrm{kPa}$ of pressure, the upper plate (without and with additional mass) rested on the mattress for the duration of each test.

- Inflation pressure. Each mattress was tested at three inflation pressures: $2.5,3.5$, and $4.5 \mathrm{kPa}$. The pressure was measured using a WIKA digital pressure gauge prior to testing (WIKA Alexander Wiegand SE \& Co. KG, Klingenberg, Germany).

- Mattress size. Both mattress types were tested as full-size mattresses and custom-size mattresses. The custom-size mattresses were manufactured to be shorter in length but otherwise consistent with their full-size equivalent.

- Environmental conditions. Full-size mattresses were tested in two different environmental conditions: (1) standard environmental conditions $\left(20 \pm 2^{\circ} \mathrm{C} / 65 \pm 4 \% \mathrm{RH} /\right.$ still air) and (2) a low-temperature environment $\left(10 \pm 2^{\circ} \mathrm{C} / 65 \pm 4 \% \mathrm{RH} / \mathrm{still}\right.$ air). Lower temperatures could not be achieved while maintaining the standard humidity level. For both conditions, the temperature of the upper plate remained at $35^{\circ} \mathrm{C}$ and the lower plate at $20^{\circ} \mathrm{C}$.

- Supplementary insulation. Each mattress was tested in four configurations in standard environmental conditions: (a) standard setup, (b) with an additional supportive frame, (c) half insulation-tested with an additional supportive frame and insulation over the non-test portion of the mattress excluding the head

${ }^{5}$ Conditions in which independent test results are obtained with the same method on identical test items in the same laboratory by the same operator using the same equipment within short intervals of time [2]. 
FIG. 4 Configurations for investigating the effect of supplementary insulation: (a) standard test setup, (b) with a supportive frame, (c) half insulation, and (d) full insulation.

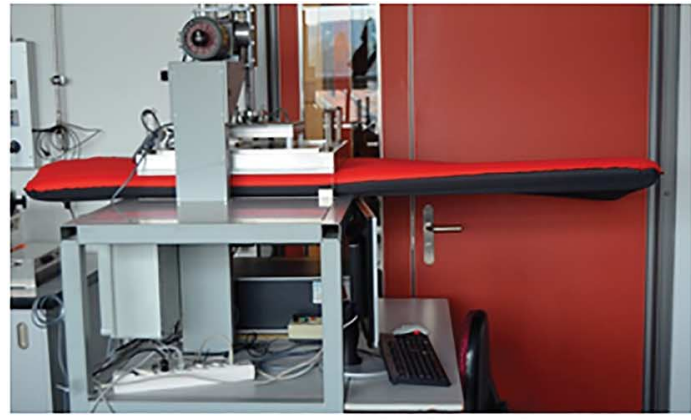

(a)

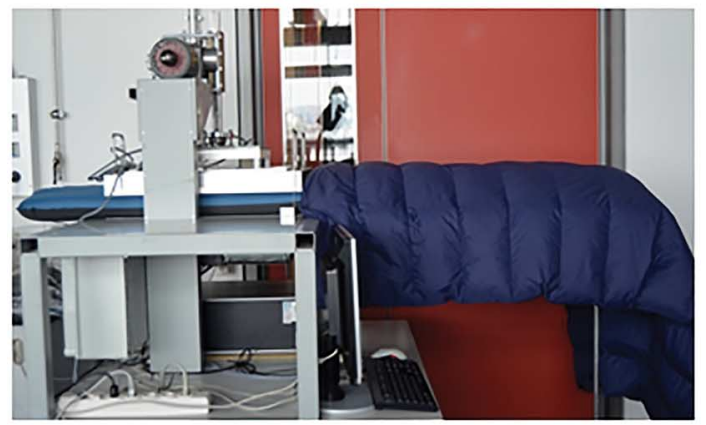

(c)

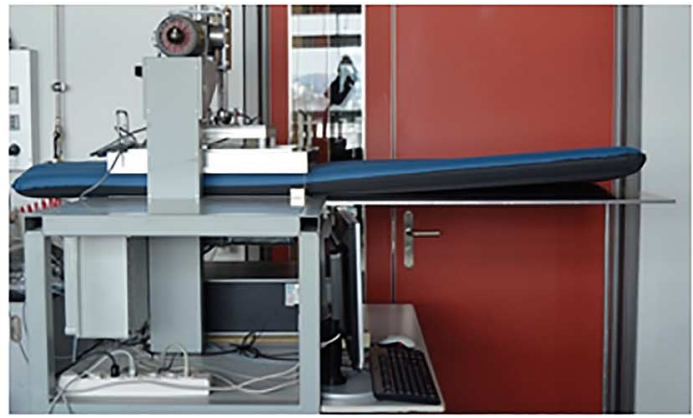

(b)

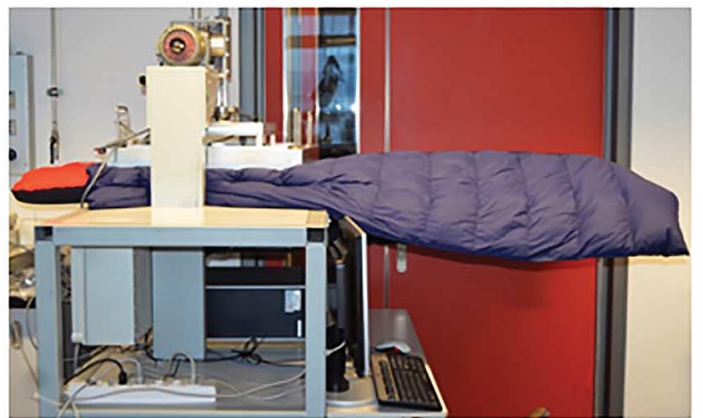

(d)

area, and (d) full insulation - tested with an additional supportive frame and insulation over the test and non-test portion of the mattress, excluding the head area (see Fig. 4).

Descriptive and inferential statistics were generated using SPSS Statistical Software (SPSS Version 22; International Business Machines Corporate, Armonk, NY) [23]. Factorial repeated-measures analysis of variance (ANOVA) was used to determine if there were significant differences in the R-value and thickness due to the temperature difference, inflation pressure, external pressure, environmental conditions, and supplementary insulation for each mattress type. Normality was assessed using the Shapiro-Wilk test. The sphericity of the data was tested using Mauchly's test. If violated $(P<0.05)$, the degrees of freedom $(\mathrm{DF})$ were corrected using Greenhouse-Geisser estimates of sphericity [23]. When the main effects were identified, post hoc comparisons were performed. Post hoc tests were corrected for the inflation of Type I error using the Bonferroni method. Factorial ANOVA was used to determine the effect of mattress size on the thickness and R-value. Levene's test for the equality of variances was used to determine the equality of variances across the groups [23]. For data with unequal variance, $\log$ transformations were applied. For all tests, statistical significance was set at $\alpha=0.05$.

\section{Results}

\section{PART ONE-REPEATABILITY}

The within-laboratory repeatability results for each of the four test specimens are provided in Table 2. The coefficients of variation for the R-value were similar for both mattress types and mattress sizes. 
TABLE 2

Within-laboratory repeatability.

\begin{tabular}{lcccc}
\hline & Mattress 1, Full-size & Mattress 1, Custom-size & Mattress 2, Full-size & Mattress 2, Custom-size \\
\hline Mean thickness $\pm \mathrm{SD}, \mathrm{mm}$ & $67.3 \pm 1.0$ & $73.2 \pm 0.5$ & $69.3 \pm 0.7$ & $73.4 \pm 0.8$ \\
Mean thermal resistance $\pm \mathrm{SD}, \mathrm{m}^{2} \mathrm{~K} / \mathrm{W}$ & $0.347 \pm 0.009$ & $0.365 \pm 0.008$ & $0.750 \pm 0.020$ & $0.766 \pm 0.028$ \\
$\mathrm{CV}^{\mathrm{a}}$ thermal resistance, $\%$ & 2.5 & 2.3 & 2.7 & 3.7 \\
$95 \%$ repeatability limit, ${ }^{\mathrm{b}} \mathrm{m}^{2} \mathrm{~K} / \mathrm{W}$ & 0.024 & 0.023 & 0.056 & 0.079 \\
\hline
\end{tabular}

Note: ${ }^{\mathrm{a}} \mathrm{CV}$ : coefficient of variation; ${ }^{\mathrm{b}} 95 \%$ repeatability limit: the value below which the absolute difference between two individual test results obtained under repeatability conditions may be expected to occur with a probability of approximately $95 \%$ [2,31], calculated as 2.8 times the repeatability SD.

\section{PART TWO-TEST PARAMETERS}

Descriptive statistics for each test parameter, split by mattress type, are provided in Table 3. The significance of differences in the thickness and R-value due to the modification of each test parameter is provided in Tables 4 and 5, respectively. For the thickness and R-value, Mauchly's test of sphericity was not significant for all the measured test parameters (temperature difference, external pressure, inflation pressure, and insulation), and the sphericity was therefore assumed. For environmental conditions, the sphericity was assumed, as there are only two test conditions [23]. For the independent test parameter mattress size, Levene's test for the equality of variance was significant for the thickness but not for the R-value. The inequality of the variance for the R-value was corrected using a log transformation.

\section{TABLE 3}

Descriptive statistics for each test parameter, split by mattress type.

\begin{tabular}{|c|c|c|c|c|c|}
\hline & & \multicolumn{2}{|c|}{ Mean Thickness $\pm \mathrm{SD}, \mathrm{mm}$} & \multicolumn{2}{|c|}{ Mean R-value $\pm S D, m^{2} K / W$} \\
\hline & & Mattress 1 & Mattress 2 & Mattress 1 & Mattress 2 \\
\hline \multirow[t]{4}{*}{ Temperature difference } & $5^{\circ} \mathrm{C}$ & $68.2 \pm 0.2$ & $69.1 \pm 1.7$ & $0.266 \pm 0.011$ & $0.559 \pm 0.011$ \\
\hline & $10^{\circ} \mathrm{C}$ & $67.5 \pm 0.5$ & $68.8 \pm 1.0$ & $0.316 \pm 0.009$ & $0.674 \pm 0.006$ \\
\hline & $15^{\circ} \mathrm{C}^{\mathrm{b}}$ & $67.4 \pm 0.3$ & $67.7 \pm 1.6$ & $0.338 \pm 0.005$ & $0.724 \pm 0.015$ \\
\hline & Difference between means, $\%^{\mathrm{a}}$ & $-0.7(-1 \%)$ & $-1.4(-2 \%)$ & $0.072(24 \%)$ & $0.165(26 \%)$ \\
\hline \multirow[t]{4}{*}{ External pressure } & $0 \mathrm{kPa}$ & $81.3 \pm 0.5$ & $79.7 \pm 1.3$ & $0.430 \pm 0.015$ & $0.837 \pm 0.033$ \\
\hline & $2 \mathrm{kPa}^{\mathrm{b}}$ & $67.4 \pm 0.3$ & $67.7 \pm 1.6$ & $0.338 \pm 0.005$ & $0.724 \pm 0.015$ \\
\hline & $3 \mathrm{kPa}$ & $62.7 \pm 0.6$ & $62.3 \pm 0.6$ & $0.319 \pm 0.007$ & $0.686 \pm 0.003$ \\
\hline & Difference between means, ${ }^{\mathrm{a}}$ & $-18.6(-26 \%)$ & $-17.4(-24 \%)$ & $-0.111(-30 \%)$ & $-0.152(-20 \%)$ \\
\hline \multirow[t]{4}{*}{ Inflation pressure } & $2.5 \mathrm{kPa}$ & $63.7 \pm 0.6$ & $62.9 \pm 0.2$ & $0.336 \pm 0.015$ & $0.714 \pm 0.015$ \\
\hline & $3.5 \mathrm{kPa}^{\mathrm{b}}$ & $67.4 \pm 0.3$ & $67.7 \pm 1.6$ & $0.338 \pm 0.005$ & $0.724 \pm 0.015$ \\
\hline & $4.5 \mathrm{kPa}$ & $70.1 \pm 0.7$ & $70.7 \pm 0.9$ & $0.351 \pm 0.002$ & $0.735 \pm 0.025$ \\
\hline & Difference between means, $\%^{\mathrm{a}}$ & $6.4(10 \%)$ & $7.8(12 \%)$ & $0.015(4 \%)$ & $0.022(3 \%)$ \\
\hline \multirow[t]{3}{*}{ Mattress size } & Full-size ${ }^{\mathrm{b}}$ & $67.4 \pm 0.3$ & $67.7 \pm 1.6$ & $0.338 \pm 0.005$ & $0.724 \pm 0.015$ \\
\hline & Custom-size & $72.6 \pm 0.9$ & $73.4 \pm 0.8$ & $0.358 \pm 0.003$ & $0.741 \pm 0.012$ \\
\hline & Difference between means, $\%^{\mathrm{a}}$ & $5.2(7 \%)$ & $5.7(8 \%)$ & $0.020(6 \%)$ & $0.017(2 \%)$ \\
\hline \multirow[t]{3}{*}{ Environmental conditions } & Standard ${ }^{\mathrm{b}}$ & $67.4 \pm 0.3$ & $67.7 \pm 1.6$ & $0.338 \pm 0.005$ & $0.724 \pm 0.015$ \\
\hline & Cold & $64.6 \pm 0.4$ & $65.1 \pm 0.8$ & $0.276 \pm 0.002$ & $0.639 \pm 0.011$ \\
\hline & Difference between means, $\%^{\mathrm{a}}$ & $-2.8(-4 \%)$ & $-2.6(-4 \%)$ & $-0.061(-20 \%)$ & $-0.085(-12 \%)$ \\
\hline \multirow[t]{5}{*}{ Insulation } & Standard ${ }^{\mathrm{b}}$ & $67.4 \pm 0.3$ & $67.7 \pm 1.6$ & $0.338 \pm 0.005$ & $0.724 \pm 0.015$ \\
\hline & With frame & $68.2 \pm 0.1$ & $68.5 \pm 1.1$ & $0.336 \pm 0.004$ & $0.735 \pm 0.006$ \\
\hline & Half insulation & $68.1 \pm 0.3$ & $68.3 \pm 1.2$ & $0.343 \pm 0.004$ & $0.720 \pm 0.020$ \\
\hline & Full insulation & $72.2 \pm 0.6$ & $72.7 \pm 0.8$ & $0.404 \pm 0.007$ & $0.783 \pm 0.007$ \\
\hline & Difference between means, $\%^{\mathrm{a}}$ & $4.7(7 \%)$ & $4.9(7 \%)$ & $0.066(18 \%)$ & $0.058(8 \%)$ \\
\hline
\end{tabular}

Note: ${ }^{\text {a }}$ The difference in the group means between the highest and lowest test variable; for insulation, it is the difference between standard conditions and full insulation. In parentheses is the percentage difference; ${ }^{b}$ Indicates the default test parameter. 
TABLE 4

Thickness. Test statistics for the effect of temperature difference, external pressure, internal pressure, environmental conditions, and insulation on thickness.

\begin{tabular}{|c|c|c|c|c|c|c|c|c|}
\hline \multirow[b]{2}{*}{ Test Parameter } & \multicolumn{3}{|c|}{ Main Effect } & \multicolumn{3}{|c|}{ Interaction - Test Parameter*Mattress Type } & \multicolumn{2}{|c|}{ Post Hoc } \\
\hline & $\mathrm{DF}$ & $\mathrm{F}$ & $P$ & $\mathrm{DF}$ & F & $P$ & Pairwise & $P$ \\
\hline \multirow[t]{3}{*}{ Temperature difference } & 2,8 & 6.42 & 0.022 & 2,8 & 1.30 & $0.324(\mathrm{NS})$ & $5^{\circ} \mathrm{C} \& 10^{\circ} \mathrm{C}$ & 0.199 (NS) \\
\hline & & & & & & & $5^{\circ} \mathrm{C} \& 15^{\circ} \mathrm{C}$ & 0.002 \\
\hline & & & & & & & $10^{\circ} \mathrm{C} \& 15^{\circ} \mathrm{C}$ & 0.204 (NS) \\
\hline \multirow[t]{3}{*}{ External pressure } & 2,8 & $1,239.21$ & $<0.001$ & 2,8 & 3.25 & 0.093 (NS) & $0 \& 2 \mathrm{kPa}$ & $<0.001$ \\
\hline & & & & & & & $0 \& 3 \mathrm{kPa}$ & $<0.001$ \\
\hline & & & & & & & $2 \& 3 \mathrm{kPa}$ & 0.001 \\
\hline \multirow[t]{3}{*}{ Inflation pressure } & 2,8 & 108.62 & $<0.001$ & 2,8 & 1.15 & 0.363 (NS) & $2.5 \& 3.5 \mathrm{kPa}$ & 0.004 \\
\hline & & & & & & & $2.5 \& 4.5 \mathrm{kPa}$ & 0.001 \\
\hline & & & & & & & $3.5 \& 4.5 \mathrm{kPa}$ & 0.006 \\
\hline Environmental conditions & 1,4 & 74.92 & 0.001 & 1,4 & 0.98 & 0.767 (NS) & - & - \\
\hline \multirow[t]{3}{*}{ Insulation } & 3,12 & 70.71 & $<0.001$ & 3,12 & 0.05 & 0.986 (NS) & standard \& frame & 0.701 (NS) \\
\hline & & & & & & & standard \& half & 0.375 (NS) \\
\hline & & & & & & & standard \& full & 0.005 \\
\hline Mattress size & 1,8 & 59.24 & $<0.001$ & 1,8 & 0.11 & 0.749 (NS) & - & - \\
\hline
\end{tabular}

Note: NS: not significant at 0.05 .

TABLE 5

R-value. Test statistics for the effect of temperature difference, external pressure, internal pressure, environmental conditions, and insulation on R-value.

\begin{tabular}{|c|c|c|c|c|c|c|c|c|}
\hline \multirow[b]{2}{*}{ Test Parameter } & \multicolumn{3}{|c|}{ Main Effect } & \multicolumn{3}{|c|}{ Interaction - Test Parameter ${ }^{\star}$ Mattress Type } & \multicolumn{2}{|c|}{ Post Hoc } \\
\hline & DF & F & $P$ & $\mathrm{DF}$ & $\mathrm{F}$ & $P$ & Pairwise & $P$ \\
\hline \multirow[t]{3}{*}{ Temperature difference } & 2,8 & 137.40 & $<0.001$ & 2,8 & 20.91 & 0.001 & $5^{\circ} \mathrm{C} \& 10^{\circ} \mathrm{C}$ & $<0.001$ \\
\hline & & & & & & & $5^{\circ} \mathrm{C} \& 15^{\circ} \mathrm{C}$ & 0.001 \\
\hline & & & & & & & $10^{\circ} \mathrm{C} \& 15^{\circ} \mathrm{C}$ & 0.015 \\
\hline \multirow[t]{3}{*}{ External pressure } & 2,8 & 118.96 & $<0.001$ & 2,8 & 2.57 & $0.138(\mathrm{NS})$ & $0 \& 2 \mathrm{kPa}$ & 0.001 \\
\hline & & & & & & & $0 \& 3 \mathrm{kPa}$ & 0.001 \\
\hline & & & & & & & $2 \& 3 \mathrm{kPa}$ & 0.009 \\
\hline Inflation pressure & 2,8 & 3.28 & 0.091 (NS) & 2,8 & 0.17 & 0.845 (NS) & - & - \\
\hline Environmental conditions & 1,4 & 93.22 & 0.001 & 1,4 & 2.42 & $0.195(\mathrm{NS})$ & - & - \\
\hline \multirow[t]{3}{*}{ Insulation } & 3,12 & 47.45 & $<0.001$ & 3,12 & 1.33 & 0.311 (NS) & standard \& frame & 1.000 (NS) \\
\hline & & & & & & & standard \& half & 1.000 (NS) \\
\hline & & & & & & & standard \& full & 0.006 \\
\hline Mattress size ${ }^{\mathrm{a}}$ & 1,8 & 13.14 & 0.007 & 1,8 & 2.36 & $0.163(\mathrm{NS})$ & - & - \\
\hline
\end{tabular}

Note: NS: not significant at $0.05 .{ }^{a} \log 10$ transformation applied.

The temperature difference across the specimen had a significant effect on the mattress thickness $(P<0.05$; see Table 4) and R-value $(P<0.001$; see Table 5$)$. As the temperature difference increased from $5^{\circ} \mathrm{C}$ to $15^{\circ} \mathrm{C}$, the mean thickness of the mattress decreased, whereas the R-value increased (a difference between means of $0.072 \mathrm{~kW} / \mathrm{m}^{2}$ for Mattress Type 1 and $0.165 \mathrm{~kW} / \mathrm{m}^{2}$ for Mattress Type 2; see Table 3). For the temperature difference, a significant interaction between the R-value and mattress type was observed $(P<0.001$; see Table 5) The increase in the R-value at each temperature difference was greater for Mattress Type 2 than Mattress Type 1 (see Fig. 5). 
FIG. 5

The interaction between the mattress type and temperature difference for the R-value (error bars: $95 \%$ confidence interval).

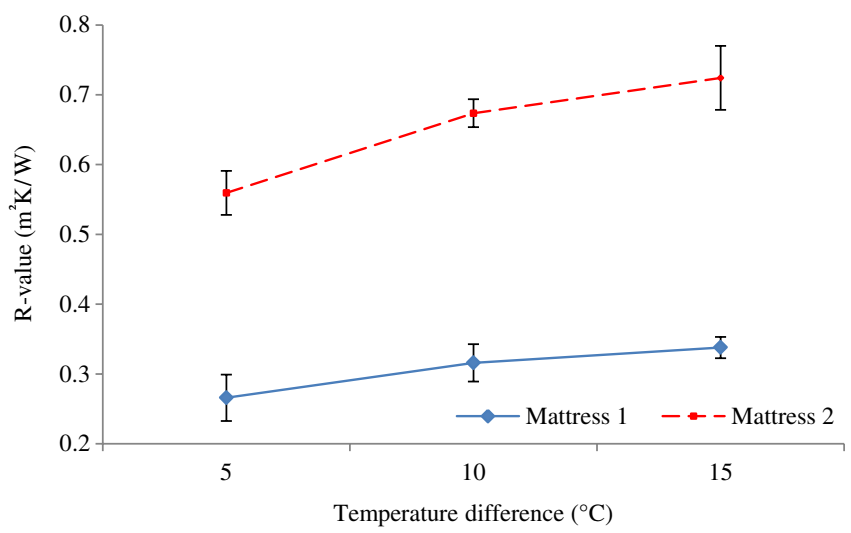

The external pressure applied had a significant effect on the mattress thickness $(P<0.001$; see Table 4$)$ and R-value $(P<0.001$; see Table 5). As the external pressure increased from 0 to $3 \mathrm{kPa}$, the mean thickness decreased, as did the R-value (a difference between means of $-0.111 \mathrm{~kW} / \mathrm{m}^{2}$ for Mattress Type 1 and $-0.152 \mathrm{~kW} / \mathrm{m}^{2}$ for Mattress Type 2).

Inflation pressure had a significant effect on the mattress thickness $(P<0.001$, see Table 4$)$, but not the $\mathrm{R}$-value $(P<0.091$; see Table 5). As the inflation pressure increased from 2.5 to $4.5 \mathrm{kPa}$, the mean thickness significantly increased. Over the range of inflation pressures investigated, the changes in the R-value were not statistically significant.

Mattress size had a significant effect on mattress thickness $(P<0.001$; see Table 4$)$ and R-value $(P<0.01$; see Table 5). In comparison to the full-sized mattresses, the custom-sized mattresses were significantly thicker and had higher R-values (a difference between the means of $0.020 \mathrm{~kW} / \mathrm{m}^{2}$ for Mattress Type 1 and $0.017 \mathrm{~kW} / \mathrm{m}^{2}$ for Mattress Type 2).

Environmental conditions had a significant effect on the mattress thickness $(P<0.01$; see Table 4$)$ and $\mathrm{R}$-value $(P<0.01$; see Table 5$)$. As the temperature of the environment decreased, the thickness and mean $\mathrm{R}$-value also decreased (a difference between means of $0.060 \mathrm{~kW} / \mathrm{m}^{2}$ for Mattress Type 1 , and $-0.085 \mathrm{~kW} / \mathrm{m}^{2}$ for Mattress Type 2).

The configuration of supplementary insulation had a significant effect on the mattress thickness $(P<0.001$; see Table 4) and R-value $(P<0.001$; see Table 5). A significant difference in the thickness and $\mathrm{R}$-value was observed between the standard setup and full insulation $(P<0.01)$. No differences in the thickness or R-value were observed between the standard setup and tests conducted with the supporting frame or half insulation.

\section{Discussion}

We have demonstrated that (1) it is possible to produce a repeatable test method for the determination of the thermal resistance of air mattresses, and (2) parameters specific to air mattress tests can influence the thickness and R-value. This work highlights the need for the standardization of both the test apparatus and test parameters.

\section{REPEATABILITY}

Repeatable outcomes could be attained when using the guarded hotplate apparatus (and tightly controlled test parameters) to determine the thermal resistance of air-filled mattresses. The mattress size and type appeared to have little effect on the repeatability. However, for mattresses that are thicker and more insulative, the current definition of steady state and data collection period may need to be adjusted. In the present study, the 
within-individual-mattress variability (repetition of the same mattress specimen in Part One) was similar in magnitude to inter-mattress variability (replicates of the same mattress type in Part Two). The confirmation of a repeatable test method enabled the investigation of the effect of modifying selected test parameters on thermal properties.

\section{THE EFFECT OF SELECTED TEST PARAMETERS}

Test parameters had significant effects on the mattress thickness or R-value, or both. The greatest influence on the $\mathrm{R}$-value, across the range investigated, was due to changes in the temperature gradient (mean percentage difference of $25 \%$ ) and external pressure ( $25 \%$ ), followed by environmental conditions (16\%). The addition of an insulative layer equated to a mean difference of $13 \%$, while inflation pressure and mattress size resulted in a $4 \%$ difference. Given the magnitude of such differences, it is clear that these parameters should be standardized to ensure the widespread comparability of results.

In this work, mattress thickness was not controlled but instead allowed to vary in accordance with the manipulated experimental parameters. An increase in sample thickness is known to be positively correlated with an increase in the thermal resistance [24-26]. Changes in thickness therefore potentially confound changes in the R-value. However, while controlling thickness may have certain advantages, it would not have been reflective of the real, practical consequences of changing such parameters and would require the manipulation of an additional variable (internal or external pressure).

Mattress thickness was influenced by all of the test parameters investigated. The greatest influence on thickness, across the range investigated, was due to changes in the external pressure (mean percentage difference of $-25 \%)$, followed by inflation pressure (11\%), mattress size (8\%), insulation (7\%), environmental conditions $(-4 \%)$, and temperature gradient $(-2 \%)$. A positive relationship between the thickness and R-value was observed for the external pressure, mattress size, and environmental conditions. Conversely, a decrease in the temperature gradient resulted in an increase in the mattress thickness and decrease in thermal resistance. For inflation pressure, an increase in the thickness was observed; however, the changes in the R-value were not significant. It is clear that thickness is not the only factor contributing to the changes in the R-value.

As the temperature difference across the mattress decreased, the mean plate temperature increased, resulting in an increase in mattress thickness and decrease in R-value. The effect of the temperature difference on the $\mathrm{R}$-value has overridden the effect of the changing thickness. The effect of modifying the temperature difference on the R-value was dependent on the mattress type, as indicated by the significant interaction. The changes observed were greater for Mattress Type 2 (air mattress with nonwoven filler) than for Mattress Type 1 (air only); this equated to percentage differences of $26 \%$ and $24 \%$, respectively. There are a couple of possible explanations for the observed effect of the temperature difference on the R-value. Firstly, as the mean plate temperature moves further away from the environmental temperature, more heat is lost to the environment, decreasing the R-value. However, if heat loss were solely responsible, it would be counterintuitive that the temperature difference had a greater influence on Mattress Type 2, as the convective movement of air within the specimen should be hindered by the nonwoven filler. Further mattress types require investigation in order to understand this fully. Secondly, as the temperature difference across the specimen decreases, the accuracy of the result may diminish $[3,6]$. Thirdly, the thermal conductivity of the polymers used in the construction of the mattresses and air retained within the mattresses are temperature dependent [27-29]. It is noted, however, that over the range of temperatures investigated, the changes in the thermal conductivity of air and common textile polymers are typically relatively small [27-29]. The increase in air temperature also causes the expansion of gas, which may account for the increase in specimen thickness.

The environmental temperature had a significant effect on the R-value of the full-size mattresses. Decreasing the environmental temperature decreased the R-value, which may be attributed to the following: (1) a decrease in the mattress thickness, which could be mitigated by inflating and conditioning the specimen at the temperature of the test environment rather than at standard conditions; or (2) a greater proportion of heat loss from the non-test portion of the mattress to the environment (see Fig. 1). Heat loss to the environment may be avoided by setting 
the mean plate temperature to the same temperature as the environment or increasing the size of the guard to match that of the specimen, with the former being the more practical option. The addition of an insulative layer was investigated as a way to mitigate heat loss to the environment and better recreate the circumstances of use. At room temperature, no difference was observed in the R-value when an insulative layer was or was not used to cover the non-test portion of the mattress (half insulation configuration). Therefore, this configuration of insulation has no advantage in terms of mitigating heat loss when tested in standard environmental conditions. The effect of insulation in cold environmental conditions was not investigated. The inclusion of the insulative layer over the test and non-test portions (full insulation configuration) did, as expected, result in an increase in the $\mathrm{R}$-value. For the full insulation configuration, the R-value of the insulative layer alone could be subtracted from the combined value to give a more relevant measure. However, the use of an insulative layer is not recommended, as it adds the potential for variation between tests and test laboratories. The addition of an insulative layer and the air gaps created by its use may also mask any small differences in the thermal properties of air mattresses.

Mattress size had a significant effect on the R-value. As the length of the mattress increased from the customto full-size mattress, the R-value decreased. The effect of mattress size on the R-value may be attributed to the change in thickness or a change in the amount of heat lost laterally through the mattress and to the environment, or both (see Fig. 1). Given that an effect was observed for mattress size, it is important that the R-value reported for a given mattress is not applied to mattresses that are consistent in construction and composition but differ in their dimensions. When the upper plate is lowered onto the custom-size mattress, the pressure is distributed evenly across the entire mattress. However, when the same plate and pressure are applied to a full-size mattress, air is forced from the test to the non-test portion of the mattress, decreasing the thickness of the test portion of the mattress. Similarly, as the external pressure applied to the full-size mattresses increases, more air is forced away from the test portion.

External pressure had a significant effect on the R-value. The decrease in the R-value can primarily be attributed to the decrease in mattress thickness associated with increasing external pressure. Changes in the pressure of the air within the mattress may have also contributed to the change in thermal resistance, as, at a given temperature, an increase in pressure results in an increase in the thermal conductivity of air and a decrease in thermal resistance [30]. Over the range investigated, the manipulation of external pressure had a greater effect on thickness than inflation pressure: the mean difference between inflation pressures of 0 and $3 \mathrm{kPa}$ was $18 \mathrm{~mm}$, and the mean difference between external pressures of 2.5 and $4.5 \mathrm{kPa}$ was $7 \mathrm{~mm}$. As a result of this greater change in thickness, the external pressure had a greater effect on the R-value than the inflation pressure. As the inflation pressure decreased, the mean R-value also decreased for both mattress types. However, over the range of inflation pressure investigated, the decrease in the R-value was not statistically significant (mean difference of $0.02 \mathrm{~m}^{2} \mathrm{~K} / \mathrm{W}$ ). There are a couple of possible explanations for this. Firstly, the range of inflation pressures investigated was not great enough. Secondly, while the pressure immediately prior to loading the mattress into the test apparatus was controlled, the pressure when the test actually commenced (reached steady state) was unknown. The inflation pressure during the test may vary between tests, depending on the specimens capacity to retain air pressure and the time taken to reach steady state (settling time). The inflation pressure at the commencement and end of the test is difficult to measure accurately, as (1) once loaded, the inflation pressure cannot currently be measured; (2) at the end of the test, the mattress may no longer in a conditioned state; and (3) air is often lost when opening the valves. Variability may be reduced by fixing the upper plate at the beginning of the test under a given load, or as a percentage of the original thickness (similar to ASTM C687-12, Standard Practice for Determination of Thermal Resistance of Loose-Fill Building Insulation). However, this approach is not representative of use and would mask the effect of any decreases in air pressure over time.

This work has made considerable progress in understanding the variables that influence the measured thermal resistance of air mattresses. While the mattresses tested were not representative of all of the mattresses currently available on the market, the significant effects observed for the two mattress types investigated support the standardization of such test parameters. Further investigations required prior to standardization include, but are not limited to, the investigation of (1) the effect of plate size (the measurement plate and thermal guard) on the 
R-value, (2) the relationship between the mattress thickness and R-value in order to ascertain the upper thickness limits or correction values for the guarded hotplate instrumentation, and (3) the validity of the test apparatus.

\section{Conclusions}

This work has shown that (1) it is possible to produce a repeatable test method for the measurement of the thermal resistance of air mattresses using a guarded hotplate apparatus in a double plate configuration and that (2) selected test parameters influence mattress thickness, thermal resistance, or both. External pressure, the temperature difference across the specimen, mattress size, use of supplementary insulation, and environmental conditions affected both the thickness and R-value of the test mattresses. Inflation pressure, over the range tested, did not have a significant effect on the R-value but did influence mattress thickness. Thus, the R-value results obtained using different test parameters are not comparable, highlighting the need for standardization of the test method. The development of such a standard would likely mitigate unacceptable levels of interlaboratory variation, which is of importance to both the consumer and manufacturer. Prior to standardization, additional work is required in order to understand the limitations and validity of air mattress tests conducted using the guarded hotplate apparatus.

\section{ACKNOWLEDGMENTS}

We would like to acknowledge Mountain Equipment Cooperative for the manufacture and supply of air mattress specimens, ASTM Subcommittee F08.22 for their continued work towards mattress test standardization, and Rolf Stämpfli, Michel Schmid, and Braid MacRae for their technical assistance.

This research received no specific grant from any funding agency in the public, commercial, or not-for-profit sectors.

\section{References}

[1] Shen, X., "Sleeping Pad Thermal Resistance (R-value) Test Method - Phase 1 Development," ASTM WK59903, 2016-unpublished

[2] ASTM E177-14, Standard Practice for Use of the Terms Precision and Bias in ASTM Test Methods, ASTM International, West Conshohocken, PA, 2014, www.astm.org

[3] ISO 8302, Thermal Insulation - Determination of Steady-State Thermal Resistance and Related Properties - Guarded Hot Plate Apparatus, International Organization for Standardization, Geneva, Switzerland, 1991, www.iso.org

[4] BS 4745, Determination of the Thermal Resistance of Textiles - Two Plate Method: Fixed Pressure Procedure, Two-Plate Method: Fixed Opening Procedure, and Single Plate Method, British Standards Institute, London, UK, 2005, www.bsigroup.com

[5] ISO 11092, Textiles - Physiological Effects - Measurement of Thermal and Water-Vapour Resistance Under Steady-State Conditions (Sweating Guarded-Hotplate Test), International Organization for Standardization, Geneva, Switzerland, 2014, www.iso.org

[6] DIN EN 12667, Thermal Performance of Building Materials and Products - Determination of Thermal Resistance by Means of Guarded Hot Plate and Heat Flow Meter Methods, Deutsches Institut für Normung, Berlin, Germany, 2001, www.din.de

[7] ISO 15831, Clothing - Physiological Effects - Measurement of Thermal Insulation by Means of a Thermal Manikin, International Organization for Standardization, Geneva, Switzerland, 2004, www.iso.org

[8] ASTM C177-13, Standard Test Method for Steady-State Heat Flux Measurements and Thermal Transmission Properties by Means of the Guarded-Hot-Plate Apparatus, ASTM International, West Conshohocken, PA, 2013, www.astm.org

[9] ASTM C687-12, Standard Practice for Determination of Thermal Resistance of Loose-Fill Building Insulation, ASTM International, West Conshohocken, PA, 2012, www.astm.org

[10] ASTM D1518-14, Standard Test Method for Thermal Resistance of Batting Systems Using a Hot Plate, ASTM International, West Conshohocken, PA, 2014, www.astm.org

[11] ISO 5085-1, Textiles - Determination of Thermal Resistance - Part 1: Low Thermal Resistance, International Organization for Standardization, Geneva, Switzerland, 1989, www.iso.org

[12] DIN EN 12939, Thermal Performance of Building Materials and Products. Determination of Thermal Resistance by Means of Guarded Hot Plate and Heat Flow Meter Methods - Thick Products of High and Medium Thermal Resistance, Deutsches Institut für Normung, Berlin, Germany, 2001, www.din.de

[13] Defloor, T., "The Effect of Position and Mattress on Interface Pressure," Appl. Nurs. Res., Vol. 13, No. 1, 2000, pp. 2-11, https://doi.org/10.1016/S0897-1897(00)80013-0 
[14] Vanderwee, K., Grypdonck, M., and Defloor, T., "Alternating Pressure Air Mattresses as Prevention for Pressure Ulcers: A Literature Review,” Int. J. Nurs. Stud., Vol. 45, No. 5, 2008, pp. 784-801, https://doi.org/10.1016/j.ijnurstu.2007.07.003

[15] Stewart, T. P., McKay, M. G., and Magnano, S., "Pressure Relief Characteristics of an Alternating Pressure System," Decubitus, Vol. 3, No. 4, 1990, pp. 26-29.

[16] Boorman, J. G., Carr, S., and Kemble, J. V., "A Clinical Evaluation of the Air-Fluidised Bed in a General Plastic Surgery Unit,” Br. J. Plast. Surg., Vol. 34, No. 2, 1981, pp. 165-168, https://doi.org/10.1016/S0007-1226(81)80087-2

[17] Ryan, D. W. and Byrne, P., "A Study of Contact Pressure Points in Specialised Beds," Clin. Phys. Physiol. Meas., Vol. 10, No. 4, 1989, pp. 331-335, https://doi.org/10.1088/0143-0815/10/4/004

[18] Bader, G. G. and Engdal, S., "The Influence of Bed Firmness on Sleep Quality," Appl. Ergon., Vol. 31, No. 5, 2000, pp. 487-497, https://doi.org/10.1016/S0003-6870(00)00013-2

[19] McCluskey, P., "Pad Comfort Pressure Survey," NEMO Equipment, (unpublished).

[20] ISO 139, Textiles - Standard Atmospheres for Conditioning and Testing, International Organization for Standardization, Geneva, Switzerland, 2005, www.iso.org

[21] ASTM D1776/D1776M-16, Standard Practice for Conditioning and Testing Textiles, ASTM International, West Conshohocken, PA, 2016, www.astm.org

[22] ASTM Subcommittee F22.08, Standard Test Method for Thermal Resistance of Camping Mattresses Using Guarded Hotplate Apparatus, WK59903, 2017, (unpublished)

[23] Field, A. P., Discovering Statistics Using SPSS, Third Ed., SAGE, London, UK, 2012, 915p.

[24] Havenith, G., "Heat Balance When Wearing Protective Clothing," Ann. Occup. Hyg., Vol. 43, No. 5, 1999, pp. 289-296, https://doi.org/10.1093/annhyg/43.5.289

[25] Wilson, C. A., Laing, R. M., and Carr, D. J., “Air and Air Spaces - the Invisible Addition to Thermal Resistance,” J. Hum. Environ. Syst., Vol. 5, No. 2, 2002, pp. 69-77, https://doi.org/10.1618/jhes.5.69

[26] Wilson, C. A., Niven, B. E., and Laing, R. M., "Estimating Thermal Resistance of the Bedding Assembly from Thickness of Materials," Int. J. Cloth. Sci. Technol., Vol. 11, No. 5, 1999, pp. 262-276, https://doi.org/10.1108/09556229910297536

[27] Stephan, K. and Laesecke, A., "The Thermal Conductivity of Fluid Air," J. Phys. Chem. Ref. Data, Vol. 14, No. 1, 1985, pp. 227-234, https://doi.org/10.1063/1.555749

[28] Bretsznajder, S., "Thermal Conductivities of Gases," Prediction of Transport and Other Physical Properties of Fluids, Pergamon Press, Oxford, UK, 1971, pp. 240-288, https://doi.org/10.1016/B978-0-08-013412-3.50008-8

[29] Yang, Y., “Thermal Conductivity," Physical Properties of Polymers Handbook, Second Ed., J. E. Mark, Ed., Springer, New York, NY, 2007, pp. 155-164, https://doi.org/10.1007/978-0-387-69002-5

[30] Minter, C. C., "Effect of Pressure on the Thermal Conductivity of a Gas," NRL Report 5907, Armed Services Technical Information Agency, Washington, DC, 1963, 29p.

[31] Bartlett, J. W. and Frost, C., "Reliability, Repeatability and Reproducibility: Analysis of Measurement Errors in Continuous Variables,” Ultrasound Obstet. Gynecol., Vol. 31, No. 4, 2008, pp. 466-475, https://doi.org/10.1002/uog.5256 